\title{
DISCUSSION.
}

Mr. W. R. Bousfield, K.C., M.P. (communicated): I do not think we leserve to have our knuckles rapped quite so sharply. Professor Walker las ot set out enough of my observations to show the point to which chey 'ere directed. The paragraph introducing the quotation given by hinl runs follows :-

"It was pointed out by Dr. Lowry and myself (Proc. $R$. S 5902, lxxi.

$8)$, that the viscosity temperature co-efficients and the conductivity rature co-efficients for 'water' were practically idetical, and this at first seem to support the view that the $\mathrm{H}$ and $\mathrm{OH}$ ios are anhydrous, Wied rmann's Annalen, 53, 209; Zeitschrift für physika Chem., I4, 317. 


\section{THE IONS OF PURE WATER}

Jentity of the co-efficients would be consistent with the view th. of the conducting ions did not change with temperature. Bus zonsideration displaces this view."

n follows the quotation given by Professor Walker.

ieference to the original will show that I used the term "water" in ted commas throughout. Professor Walker says :-

Kohlrausch emphasises the fact that he is not dealing with even approxitely pure water, by putting ' wasser' within inverted commas."

It is curious that Professor Walker fails to note that my inverted commas had precisely the same meaning as those of Kohlrausch, and that I did not profess to be dealing with pure water. My point was to show that the coincidence of the viscosity and temperature co-efficients for "water" did not support the view of anhydrous $\mathrm{H}$ and $\mathrm{OH}$ ions, since these were not the ions upon which the conductivity of "water" depended.

The passage quoted from my observations is therefore perfectly correct as applied to the matter with which I was dealing.

Further on I made the observation that "it is doubtful whether water pcssesses any autolytic conductivity whatever," which may have led Dr. Lowry and Professor Walker to think that the preceding passage had reference to pure w ter. This scepticism as to the conductivity of pure water I have hitherto $\mathrm{l}_{\mathrm{L}}$ ared with some physicists of undoubted eminence. But I now agree that thi: doubt inust be considered to be finally removed by the present Paper. There was already strong evidence leading to the view that pure water had a genuine conductivity due to $\mathrm{H}$ and $\mathrm{OH}$ ions. But that this evidence was not considered to be quite conclusive, may, I think, be gathered from the way in which Professor Walker himself refers to the matter in his "Introduction to Physical Chemistry" (ed. I9O3, p. 289). He says, referring to the conductivity which Kohlrausch had obtained for the conductivity of his pursst water :-

"This conductivity must be accepted as the specific conductivity of pure water, for it is in close accordance with the numbers calculated from the chemical and electrical behaviour of the substance. If the conductivity is not due to dissolved impurity, the ions with which the electricity travels must come from the water itself. Since water contains only hydrogen and oxyge the ions we should expect are hydrion and hydroxion. This assumpti accounts very well for the chemical and electro-chemical behaviour of w? and affords the desired basis of a numerical comparison between the re of the different investigations." (The italics are mine.)

The hypothetical mode of statement which Professor Walker adopts $\mathbf{j}$ a:bove passage is in conformity with the view that the evidence thowwas not convincing. A perusal of Kohlrausch and Heydweily. $\therefore$ how that it did not clearly bring out the identity of ${ }^{\circ}$ u oretical temperature co-efficients. It may no doubt bo inves tigation, but it is concealed by the form of express* observa uns criticised, I gave the theoretical expression of pure $u$ iter as derived from that of the $\mathrm{H}$ and $\mathrm{OH}$ io

$$
\kappa=m \times\left(\mathrm{r}+0^{\circ} \mathrm{or}_{3} \mathrm{~T}-\mathrm{o}^{\circ} \mathrm{oono} \mathrm{r}^{\circ}\right.
$$

Professor Walker has adopted this form, and ' variation of $m$ i, a similar form, has clearly observed temperature co-efficients of pure wat temperature co-efficients deduced from those of this demonstration clearly shows that the upon the $\mathrm{H}$ and $\mathrm{OH}$ ions. I think the " 


\section{THE IONS OF PURE WATER}

ofessor Walker guarded himself in the above quoted passage $n$ lispensed with.

I may add that, before we knew of Professor Walker's Paper, D, and I had discussed the applicability of the above equation to pure $\mathrm{u}$ connection with the Paper of Kohlrausch and Heydweiller, and had ob. that in order to apply this equation to pure water, the effect of $n$ temperature in increasing the ionisation of the water would have to brought into account. This consideration dnes not apply to "water."

Professor Walker (communicated reply) : I regret to have misunde stood Mr. Bousfield. It was, I think, only natural for Dr. Lowry and mysel. to suppose that $\mathrm{Mr}$. Bousfield, in the passage which I have quoted, was under the impression that the "water" he referred to was pure water, since it is surely quite unnecessary to consider the temperature co-efficients of the hydrogen and hydroxide ions in connection with impure water, the conductivity of which cannot possibly be due to these ions, 